\title{
LARYNGOLOGY
}

\section{The role of laryngectomy in locally advanced thyroid carcinoma. Review of 16 cases}

\author{
Il ruolo della laringectomia nel carcinoma della tiroide localmente avanzato. \\ Revisione di 16 casi
}

\author{
A.I. CHALA', S. VÉLEZ², A. SANABRIA ${ }^{3}$ \\ ${ }^{1}$ Head and Neck Surgery Service, School of Medicine, Universidad de Caldas, Manizales, Colombia; ${ }^{2}$ School of \\ Medicine. Universidad de Antioquia, Medellín, Colombia; ${ }^{3}$ School of Medicine, Universidad de Antioquia, Fundación \\ Colombiana de Cancerología Clínica Vida, Medellín, Colombia
}

\section{SUMMARY}

Locally advanced disease with larynx invasion is a challenge to the surgeon, but laryngectomy is almost never necessary in thyroid carcinoma. The aim of this study was to review the clinical outcomes of patients with locally advanced thyroid carcinoma invading the larynx who underwent laryngectomy. A case series of patients treated in a tertiary care hospital was reviewed. Data about the type of operation, method of reconstruction, complications and overall survival of 16 patients operated on between 2002 and 2015 with larynx invasion is presented. There were 10 females. The mean age was $63 \pm 8.8$ years. Besides total thyroidectomy and neck dissection, four patients underwent total pharyngolaryngectomy, 11 total laryngectomy and one hemi-laryngectomy. Reconstruction was made with regional flaps in 10 patients (7 pectoral/Bakamjian flaps and 3 gastric pull-through procedures) and a jejunum free flap in one patient. Two patients needed carotid artery reconstruction. Five tumours were classic (conventional) papillary carcinoma variants, while the others were aggressive histological varieties (insular, tall cell, sclerosing). The mean tumour size was $4.3 \pm 1.6 \mathrm{~cm}$. All tumours had lymphovascular invasion and 12 had positive lymph nodes. Concomitantly, oesophageal/hypopharyngeal invasion was present in 7 cases and invasion of carotid vessels in 2 cases. There were two postoperative deaths and two anastomotic leaks that were treated conservatively. The mean overall survival was $31 \pm 33$ months (median 27.6 months, range 0-120). Laryngectomy is an alternative surgical procedure to control selected cases of advanced thyroid carcinoma that offers good local control and long term survival.

KEY WORDS: Thyroid cancer $\bullet$ Laryngectomy $\bullet$ Surgery $\bullet$ Neck dissection

\section{RIASSUNTO}

Le malattie localmente avanzate con invasione della laringe sono una sfida per il chirurgo, tuttavia la laringectomia non si rende quasi mai necessaria nel carcinoma della tiroide. L'obiettivo di questo studio è stato quello di valutare gli outcomes clinici di quei pazienti sottoposti a laringectomia per carcinoma della tiroide localmente avanzato con invasione della laringe. Sono stati inclusi una serie di pazienti trattati in presidi ospedalieri di terzo livello. Pertanto sono stati raccolti i dati riguardo il tipo di intervento, la modalità di ricostruzione, le complicanze e la sopravvivenza di sedici pazienti operati tra il 2002 e il 2015. Tra questi, 10 erano donne; l'età media era di $63 \pm 8,8$ anni. Oltre alla tiroidectomia totale e alla dissezione del collo, quattro pazienti sono stati sottoposti a faringolaringectomia, undici a laringectomia, e uno ad emilaringectomia. La ricostruzione è stata effettuata con lembi regionali in dieci pazienti (7 lembi di pettorale e 3 procedure di pull-though gastrico) e lembo libero di digiuno in un paziente. Per due pazienti si è resa necessaria la ricostruzione dell'arteria carotide. Cinque tumori erano carcinomi papillari variante classica, gli altri erano varianti istologiche aggressive (insulare, sclerosante diffuso, a cellule alte). La dimensione media dei tumori era 4,3 \pm 1,6 cm. Tutti i tumori presentavano un'invasione linfovascolare e dodici di essi avevano dato metastasi linfonodali. Sette casi presentavano una concomitante invasione ipofaringo-esofagea, mentre due casi presentavano invasione dei vasi carotidei. Ci sono state due morti postoperatorie e due deiscenze dell'anastomosi, trattate entrambe in maniera conservativa. La sopravvivenza media è stata di $31 \pm 33$ mesi (media pari a 27,6, range 0-120). La laringectomia è una procedura chirurgica per casi selezionati di carcinoma tiroideo, che offre un buon controllo locale e lunghi tempi di sopravvivenza.

PAROLE CHIAVE: Carcinoma tiroideo $\bullet$ Laringectomia $\bullet$ Dissezione del collo

Acta Otorhinolaryngol Ital 2018;38:109-114

\section{Introduction}

Well-differentiated thyroid carcinoma has a good prognosis since patients have low risk malignancies. However, laryngotracheal invasion occurs in 7 to $13 \%$ of patients, and ${ }^{12}$ most cases are asymptomatic. In the presence of intraluminal invasion, symptoms become evident and are related to vocal cord paralysis, airway obstruction, or tumour bleeding. In these cases, extended resections are required to control the disease, sometimes affecting quality of life. 
The larynx is not invaded as frequently as the trachea or oesophagus, and its invasion is almost always associated with multivisceral spread. Fortunately, laryngectomy is seldom necessary in the treatment of locally advanced thyroid carcinoma (LATC) since even in the presence of locally advanced disease, it is possible to do a less invasive procedure without compromising long term results; this is why a radical resection is not easy to justify.

Locally advanced disease with laryngeal or cricoid invasion is a challenge to the surgeon, who must decide between partial resection, cricoid and tracheal resection, hemi-laryngectomy, or total laryngectomy, while almost always trying to solve an obstructive or bleeding complication. On the other hand, when complete resection is performed, local recurrence is infrequent ${ }^{3}$. With a less radical procedure, even when adding postoperative ${ }^{131} \mathrm{I}$ therapy or radiotherapy the relapse is still frequent and persistent growing of an intraluminal mass, followed by vocal fold paralysis, airway obstruction, and death by asphyxiation or bleeding usually occurs. There are few case reports about laryngectomy in the treatment of LATC, and the existing reports are combined with isolated tracheal invasion which are less disruptive procedures. The objective of this study is to report the clinical outcomes of a series of patients with LATC invading the larynx who underwent total laryngectomy associated with thyroidectomy and neck dissection.

\section{Materials and methods}

This is a descriptive retrospective study approved by the ethics committees of the Hospital Pablo Tobon Uribe and the Head and Neck Service of the Universidad de Caldas, Colombia. All patients with a diagnosis of LATC who underwent partial or total laryngectomy with or without other organ resection (trachea, oesophagus, vessels) were identified at both centres. The data was collected from January 1, 2002 until January 31, 2015. Patients with isolated tracheal invasion identified pre- or intraoperatively were excluded from the analysis.

Patients were considered resectable if the surgeon considered that local and regional resection could be achieved to control the disease with free margins. If the tumour invaded the pre-vertebral fascia or the mediastinum great vessels, resection was not attempted. In cases of invasion of other adjacent organs (oesophageal/pharynx or jugular vein/carotid artery), a pre-operative evaluation with a multidisciplinary team was made to plan multivisceral resection. Pulmonary and/or bone metastasis were not a contraindication to resection. Patients with severe comorbidities with a high risk of intraoperative death defined by anaesthesiologist (ASA 4-5) or poor functional status (Karnofsky index) were considered inoperable.

Before resection, fibre optic endoscopic evaluation was performed in all cases to assess the presence and location of luminal invasion, and when possible a tumour biopsy was taken. Imaging studies such as contrast-enhanced computer tomography (CT) or magnetic resonance imaging (MRI) helped to assess tumour extension before surgery.

Demographic, clinical, imaging, pathologic, treatment and prognostic variables were extracted from clinical records. The TNM staging system was used at the moment of diagnosis. Loco-regional and systemic recurrence was defined as present in those patients with imaging studies suggestive accompanied with pathologic evidence of carcinoma in the open or fine needle aspiration biopsy (FNAB). All margins were assessed by frozen section, and if positive margin resections were made. Patients were classified as incomplete (R1) or complete (R0), according to final pathology report. Follow-up time was calculated from the moment of surgery to the last clinical visit.

Decisions about diagnostic methods, treatment options and scheme of follow-up were defined by the attending surgeon. Follow-up included periodic imaging tests (ultrasound/CT or PET/CT) and serum markers measurement (TSH, thyroglobulin and anti- thyroglobulin antibodies). All patients were suppressed with high doses of levothyroxine.

Continuous variables are presented as mean and standard deviation and median-range. Categorical variables are shown as percentages. Overall and disease-free survival were calculated using the Kaplan-Meier method using the Stata 9.0 program (Stata Corp., Texas, USA).

\section{Results}

A total of 16 patients with LATC who underwent laryngectomy were identified from January 1, 2002 to January 31,2015 . Ten patients were female and six male, with a mean age of $63 \pm 8.8$ years. All patients had symptoms related with local invasion such as dysphonia, dysphagia, dyspnea, or haemoptysis at the first clinical evaluation. Three patients had a mass confined to a single thyroid lobe and 13 had disease in both lobes. Thirteen patients had concomitant cervical pathologic nodes confirmed by FNAB. All patients without previous surgery had a FNAB positive for papillary thyroid carcinoma in the gland. For cases with previous surgery, a revision of the final pathologic analysis that confirmed papillary carcinoma was done. Eleven patients had recurrent nerve paralysis at the first evaluation and none had had a previous tracheostomy. All patients underwent confirmation of laryngeal invasion 
through fibre optic endoscopy before surgical treatment. Three had a biopsy taken during the exam that was positive for papillary carcinoma.

Ten patients had been operated on in other institutions in an attempt to perform thyroidectomy: six patients presented recurrence after total thyroidectomy and a shaving procedure associated with ${ }^{131}$ I therapy; one also had previous course of radiotherapy and tracheal stent, and four patients had partial thyroidectomy with abortion of the procedure when operative findings indicated airway infiltration. Four patients had distant metastases when first seen and seven patients had concomitant invasion of the digestive tract (4 to the oesophagus and 3 to the pharynx). Patients were graded according to the TNM Staging system as stage IVa in 12 cases and stage IVc in the remaining.

Total or corresponding residual thyroidectomy with comprehensive neck dissection was performed in all cases. Four patients underwent total pharyngolaryngectomy, 11 total laryngectomy and in one case a hemi-laryngectomy was possible. Resection of adjacent structures and reconstruction is shown in Table I. The Bakamjian flap was used in 6 patients with previous radiotherapy only to cover skin defects after mucosal reconstruction and to allow reconstruction of tracheal stoma in cases of mediastinal retraction of the trachea, due to ease of its design and less operative time required. A pectoralis major myocutaneous flap was used when pharyngeal wall reconstruction was needed. The definitive pathological report showed classic (conventional) papillary carcinoma variant in five patients, follicular in two cases and the rest were aggressive histological varieties of papillary carcinoma, such as insular $(n=2)$, tall cell $(n=3)$, or sclerosing $(n=4)$. The mean tumour size was $4.3 \pm 1.6 \mathrm{~cm}$ and all tumours had lymphovascular invasion. Positive lymph nodes were found in 12 patients. Three patients had positive microscopic margins.

Fifteen patients received a postoperative dose of $150 \mathrm{mCi}$ (5550 MBq) of radioiodine ${ }^{131} \mathrm{I}$ and a complete course of radiotherapy, except the one who had undergone previous radiotherapy. Conventional radiotherapy technique was used for patients treated before 2010 and conformal 3D for those treated after 2010. A 45 Gy total dose in 1.8 Gy daily fractions were used and the field included the neck and superior mediastinum.
There were two postoperative deaths. The first was a female patient with gross invasion of common carotid artery who required a vessel graft. She developed a postoperative suture leakage that produced a carotid blowout at postoperative day 10 , with a haemorrhagic shock that required carotid ligature with brain infarct and death at the ICU at postoperative day 15 . The second, a 59-yearold female diagnosed with a gross mass invading the larynx, proximal trachea, oesophagus, left innominate vein and the common carotid artery, underwent total en-bloc thyroidectomy with pharyngolaryngectomy and neck dissection along with carotid resection with a graft, partial innominate vein resection reconstructed with a patch and gastric pull-up reconstruction. She developed a carotid graft thrombosis that required thrombectomy at postoperative day 4 . She suffered a massive brain infarction and died on postoperative day 5 .

There were three major complications; two were anastomotic leaks. One was healed with conservative management, wound care and nutrition and closed on day 23; the second was the patient who died due to carotid blowout. The third complication was a partial necrosis of the posterior wall of the trachea after total laryngectomy that required exploration and reconstruction of the stoma with a PTFE patch to replace the necrotic zone. The patient evolved properly and the patch was removed 12 weeks after surgery. During follow-up there was one local (stomal) recurrence, a regional recurrence was in two patients, so that additional neck dissection was performed. Four patients developed pulmonary metastasis treated with ${ }^{131}$ I therapy with acceptable uptake. None of the patients was considered eligible to receive systemic therapy with tyrosine-kinase inhibitors due to absence of symptoms and lack of benefit to initiate this therapy in these specific cases.

The mean follow-up time was $43 \pm 44$ months (median 26, range 1-153). The mean overall survival was $31 \pm 7$ months (median 30.6 months, range 0-120). Excluding postoperative deaths, there were no other deaths at the moment of writing. Five-year overall survival was $80.1 \%$ (Fig. 1).

\section{Discussion}

The natural history of locally invasive thyroid carcinoma without adequate treatment is growth of intraluminal tu-

Table I. Extension of surgery and reconstruction procedures for patients with locally advanced thyroid cancer who underwent laryngectomy.

\begin{tabular}{|c|c|c|c|c|c|c|c|c|c|}
\hline & \multicolumn{5}{|c|}{ Other structures resected } & \multicolumn{4}{|c|}{ Reconstruction } \\
\hline & None & Pharynx & Oesophagus & Trachea & $\begin{array}{c}\text { Large } \\
\text { vessels }\end{array}$ & Primary & $\begin{array}{l}\text { Regional } \\
\text { flap }\end{array}$ & $\begin{array}{c}\text { Gastric } \\
\text { pull-through }\end{array}$ & Free flap \\
\hline Partial laryngectomy & 0 & 0 & 0 & 0 & 0 & 1 & 0 & 0 & 0 \\
\hline Total laryngectomy & 5 & 3 & 4 & 1 & 2 & 4 & 7 & 3 & 1 \\
\hline
\end{tabular}




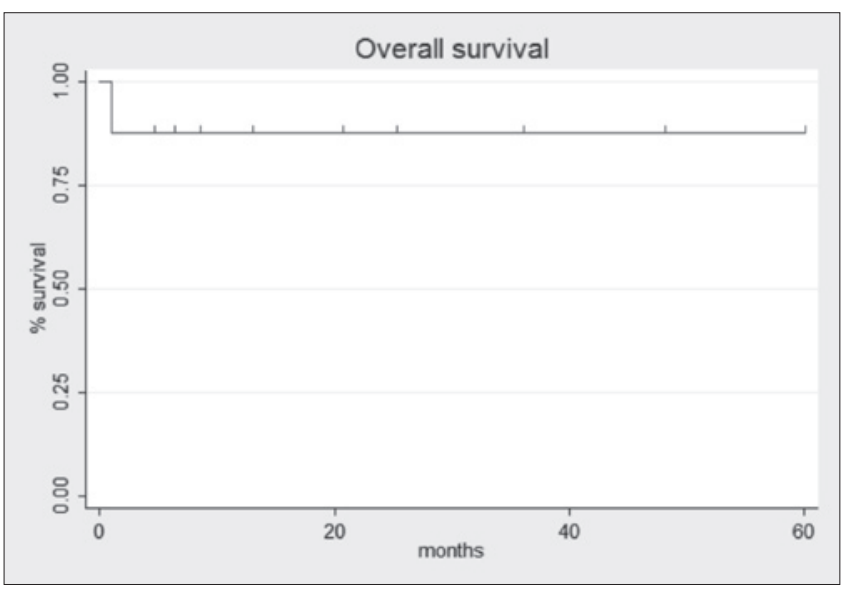

Fig. 1. Kaplan-Meier overall survival graph (months) in patients with locally advanced thyroid cancer who underwent laryngectomy (sticks over the survival line represents patients censored).

mour into the aerodigestive tract ${ }^{4}$. Many of these locally invasive tumours correspond to aggressive variants of papillary carcinoma or poorly differentiated thyroid carcinomas, which behaviour have been extensively reported in literature ${ }^{56}$. Commonly, a paralysis of one or both vocal cords due to recurrent laryngeal nerve involvement is the first event followed by a progressive invasion of the cricoid, the trachea or the oesophagus and tumour erosion of the laryngeal cartilage with invasion of the larynx ${ }^{7}$. Still, there is no consensus in the pattern of invasion. Two routes have been proposed to explain laryngeal invasion: one by local direct invasion from the primary tumour and a second by a metastatic lymph node extension through extracapsular node spread ${ }^{8}$. The patients in this series showed local invasion through the laryngeal cartilage, usually associated with hypopharynx, oesophagus, or cricoid invasion, some of which were related to a bulky node with extracapsular spread, making it impossible to differentiate the pattern of invasion. One case treated initially with a shaving procedure, radiotherapy and endotracheal stent exhibited tumour growing through the tracheal lumen ascending to the cricoid and larynx and causing tumour bleeding and emergency airway obstruction. Additionally, vessel invasion was found in some cases needing vascular grafts, which describes the degree of local invasion. Similar to other reports, a history of voice changes, dysphagia, haemoptysis, dyspnoea and stridor was present, especially in patients with a bulky fixed tumour. This finding should alert the physician to inquire about more advanced disease ${ }^{9}$, to perform a fibre optic endoscopic evaluation and if possible, to obtain a tumour biopsy. We confirmed only three cases with endoluminal tumour biopsy, likely due to the potential risk of fatal bleeding.

The imaging studies such as contrast-enhanced tomogra- phy $(\mathrm{CT})$ or magnetic resonance imaging (MRI) helped to clarify the luminal extent, and size of the tumour as well as to prepare the major resection, although in some cases the techniques were not able to identify the degree of invasion. Therefore, when CT or MRI shows cartilage gross spread, vocal cord or hypopharynx involvement, it must alert the surgeon to be prepared to make a major resection such as a total laryngectomy or pharyngolaryngectomy, keeping in mind that it should be discussed with the patient, while realising the goals of care and expectancies with regards to voice and swallowing preservation. Additionally, a deep discussion of potential complications such as fistula, bleeding, wound dehiscence, vascular outbreak, permanent tracheostomy, sepsis, or a fatal consequence as death should be conducted. Therefore, intervention of palliative care services to address goals of care, advanced directives and potential symptoms management should be taken in consideration prior to surgical intervention.

Laryngeal involvement in cases of thyroid carcinoma is rare, so that specific recommendations cannot be made and the treatment must be individualised. The largest series of laryngectomy in cases of LATC was published by Ballantyne in $1994{ }^{3}$ with 32 patients (27 total laryngectomy and 5 pharyngolaryngectomies). He included patients with undifferentiated and anaplastic histology and medullary tumours, as well as patients with isolated tracheal or oesophageal invasion. He reported only one postoperative death and two carotid blowouts and 5 fistula that were treated conservatively. Nine patients developed locoregional recurrence during follow-up, and overall survival was around $75 \%$ at 5 years. Gaissert et al. ${ }^{10}$ reported on 82 patients, of which $75 \%$ corresponded to WDTC; 13 underwent total laryngectomy/laryngopharyngectomy, with a frequency of complete resection of $61 \% .56 \%$ of these patients had a previous thyroidectomy, and $30 \%$ had received previous radiotherapy. The mean survival was 5.5 years with an overall survival of $38 \%$ at 5 years. Other authors have reported cases series with less than 10 patients ${ }^{11-17}$ with similar results. In the cases reported, the decision of surgical treatment was made due to the large tumour volume with larynx or hypopharynx destruction that produced bleeding, dyspnoea, stridor, dysphagia and pain related to local invasion to soft tissues; in some cases as a consequence of a recurrent or persistent progressive invasion in spite of the treatments performed with no other alternative therapies. However, it is difficult to derive a more general conclusion from these studies due to inclusion of tumours of different histology, clinical stage and previous treatments. A recent consensus document from the American Head and Neck Society supports shave excision of tumours with partial thickness invasion of the oesophagus or larynx, but a composite tumour 
excision (oesophagectomy, laryngectomy) for those with gross invasion, as reported in this study ${ }^{18}$.

The surgical possibilities includes shaving, partial laryngectomy and total laryngectomy ${ }^{19}$. Shaving procedures are not considered as a feasible alternative in cases of large tumours due to the risk of leaving viable tumour and late local recurrence. Most groups consider that shaving can only be offered when there is no gross invasion of the perichondrium. In cases of gross luminal invasion or extensive laryngeal invasion, partial or total laryngectomy is the ideal procedure ${ }^{20}$, because it completely removes the tumour, relieves the obstruction and bleeding symptoms and avoids death by asphyxia. The decision of the type of operation is based on experience with surgical techniques of en-bloc resection, the patient's physical condition and the availability of other surgical teams such as vascular surgeons, thoracic surgeons and reconstructive surgeons, but the main factor is a high preoperative probability of complete resection of the tumour. Indications for the type of laryngectomy depend on location of the tumour, depth of invasion and extension of the tumour. Moritani ${ }^{21}$ reported on the feasibility of partial laryngectomy in 12 of 15 patients with intraluminal invasion, while Hartl et al., performed partial laryngectomy in 5 of 12 patients ${ }^{22}$. Laryngeal preserving surgery was possible in only one case herein. It is important to realise that we were dealing with very large tumours that commonly involve the larynx or even the pharynx circumferentially. Independent of the larynx subsites involved, if the thyroid tumour externally surpasses the limits of the larynx or pharynx, a total or extended procedure must be done in order to obtain free tridimensional margins, which is the principle of oncologic surgery. If the surgeon believes that R0 surgery is not possible to obtain, we do not recommend resection. Simultaneously, when local control is achieved, it is possible to offer systemic therapy with ${ }^{131}$ I for cases with distant metastasis.

In cases of recurrent disease after a thyroid invasive cancer previously treated with a conservative procedure, even with postoperative ${ }^{131}$ I therapy or a complete course of postoperative radiotherapy and the additional hostile field, en-bloc resection of the tumour and involved surrounding structures helps to obtain negative margins with consequent improvement in long-term local control ${ }^{16} 23$. Retrospective studies in patients with laryngectomy have shown an increase in survival comparing with shaving procedures when the complete resection of the gross disease is completely achieved ${ }^{310}$. Due to the brevity of follow-up, this series cannot document a major improvement in survival, but most patients had relief of obstructive or bleeding symptoms without evidence of local relapse. A 5-year overall survival larger than $80 \%$ is a promising number that supports this type of aggressive procedure. Regarding vascular invasion, the two patients with large vessels resection died in the immediate postoperative period. There are few reports of successful resection and reconstruction of large vessels ${ }^{24-26}$. Due to these results, we recommend to make a preoperative plan in conjunction with vascular surgery in cases suspicious of vascular invasion to guarantee good oncologic resection and functional results.

The type of reconstruction was selected based on the extension of pharynx resection. For most patients, regional flaps were used due to the resection of pharyngeal mucosa that made primary closure impossible without stenosis or to cover a skin defect due to retraction of tissues after radiotherapy. Although the Bakamjian flap has been progressively replaced by other types of flaps, it is used due to the low bulk it provides and the less operative time to build it in comparison with free flaps. Circumferential reconstruction with stomach or jejunum was offered to patients with oesophageal invasion in which the surgeon suspected a high risk of fistula if a regional flap was used. In comparison with free flaps and gastric pull-trough procedures, regional flaps have the advantage of less operative time and systemic impact and can be used in patients with comorbidities that make other procedures riskier.

Although only one partial laryngectomy was performed, it has been recommended that whenever possible, it should be attempted to preserve the quality of life related with voice preservation, without sacrificing oncologic principles ${ }^{27}$. Only four patients with total laryngectomy were suitable to the provox system rehabilitation due to the type of reconstruction (gastric pull-through or jejunum flap), but it is recommended whenever possible ${ }^{28}$.

\section{Conclusions}

Even if there is no high-level evidence due to low numbers of cases and heterogeneity of tumours and stages, partial or total laryngectomy and even pharyngolaryngectomy provides an alternative to control selected cases of WDTC with laryngeal or hypopharyngeal invasion, especially when a less radical procedure is not feasible. An exenteration procedure also seems to improve long-term local control. The surgeon should be prepared to suspect gross invasion and to manage it during the surgical intervention. The consequences of the surgical procedure should be discussed with the patient preoperatively.

\section{References}

1 Shelton VK, Skolnik EM, Berlinger FG, et al. Laryngotracheal invasion by thyroid-carcinoma. Ann Otol Rhinol Laryngol 1982;91:363-9. 
2 Chala A. Abordaje del carcinoma de tiroides invasivo a traqueolaringe y grandes vasos. Rev Colomb Cir 2002;17:10-21.

3 Ballantyne AJ. Resections of the upper aerodigestive tract for locally invasive thyroid cancer. Am J Surg 1994;168:636-9.

4 Kim AW, Maxhimer JB, Quiros RM, et al. Surgical management of well-differentiated thyroid cancer locally invasive to the respiratory tract. J Am Coll Surg 2005;201:619-27.

5 Akaishi J, Sugino K, Kameyama K, et al. Clinicopathologic features and outcomes in patients with diffuse sclerosing variant of papillary thyroid carcinoma. World J Surg 2015;39:1728-35.

6 Okuyucu K, Alagoz E, Arslan N, et al. Clinicopathologic features and prognostic factors of tall cell variant of papillary thyroid carcinoma: comparison with classic variant of papillary thyroid carcinoma. Nucl Med Commun 2015;36:1021-5.

7 Segal K, Abraham A, Levy R, Schindel J. Carcinomas of the thyroid gland invading larynx and trachea. Clin Otolaryngol 1984;9:21-5.

8 Machens A, Hinze R, Lautenschlager C, et al. Thyroid carcinoma invading the cervicovisceral axis: routes of invasion and clinical implications. Surgery 2001;129:23-8.

9 Talpos GB. Tracheal and laryngeal resections for differentiated thyroid cancer. Am Surg 1999;65:754-9; discussion 759-60.

10 Gaissert HA, Honings J, Grillo HC, et al. Segmental laryngotracheal and tracheal resection for invasive thyroid carcinoma. Ann Thorac Surg 2007;83:1952-9.

11 Zbaren P, Nuyens M, Thoeny HC, et al. Laryngeal involvement by differentiated thyroid carcinoma. Am J Surg 2005;190:153-5.

12 Cody HS, 3rd, Shah JP. Locally invasive, well-differentiated thyroid cancer. 22 years' experience at Memorial Sloan-Kettering Cancer Center. Am J Surg 1981;142:480-3.

13 Omura K, Kanehira E, Kawakami K, et al. Pharyngolaryngoesophagectomy for well-differentiated papillary thyroid carcinoma widely invading the upper aerodigestive tract. Surgery 2002;132:885-8.

14 Mattavelli F, Bombardieri E, Collini P, et al. Role of surgery in treatment of advanced differentiated thyroid carcinomas. Acta Otorhinolaryngol Ital 2007;27:62-7.

15 Jeannon JP, Simo R, Wallwork B, et al. Surgical management of advanced differentiated thyroid cancer - introducing the concept of wide field total thyroidectomy: how we do it. Clin Otolaryngol 2009;34:161-4.
16 Kim KH, Sung MW, Chang KH, et al. Therapeutic dilemmas in the management of thyroid cancer with laryngotracheal involvement. Otolaryngol Head Neck Surg 2000;122:763-7.

17 Shadmehr MB, Farzanegan R, Zangi M, et al. Thyroid cancers with laryngotracheal invasion. Eur J Cardiothorac Surg 2012;41:635-40.

18 Shindo ML, Caruana SM, Kandil E, et al. Management of invasive well-differentiated thyroid cancer: an American Head and Neck Society consensus statement. AHNS consensus statement. Head Neck 2014;36:1379-90.

19 Price DL, Wong RJ, Randolph GW. Invasive thyroid cancer: management of the trachea and esophagus. Otolaryngol Clin North Am 2008;41:1155-68, ix-x.

20 Djalilian M, Beahrs OH, Devine KD, et al. Intraluminal involvement of the larynx and trachea by thyroid cancer. Am J Surg 1974;128:500-4.

21 Moritani S. Surgical management of laryngeal invasion by papillary thyroid carcinoma: a retrospective analysis. Thyroid 2015;25:528-33.

22 Hartl DM, Zago S, Leboulleux S, et al. Resection margins and prognosis in locally invasive thyroid cancer. Head Neck 2014;36:1034-8.

23 Brauckhoff M, Machens A, Thanh PN, et al. Impact of extent of resection for thyroid cancer invading the aerodigestive tract on surgical morbidity, local recurrence, and cancerspecific survival. Surgery 2010;148:1257-66.

24 Kobayashi S, Miyakawa M, Sugenoya A, et al. Reconstruction of the carotid artery using a temporary shunt during an operation for advanced thyroid carcinoma - a case report. Jpn J Surg 1988;18:592-4.

25 Lee YS, Chung WY, Chang HS, et al. Treatment of locally advanced thyroid cancer invading the great vessels using a Y-shaped graft bypass. Interac Cardiovasc Thorac Surg 2010;10:1039-41.

${ }^{26}$ Urabe Y, Kato S, Fujii M, et al. [Surgical reconstruction of the common carotid artery by an ePTFE graft for invasive thyroid cancer: a case report]. No Shinkei Geka 2003;31:1105-9.

27 Ozturk K, Akyildiz S, Makay O. Partial laryngectomy with cricoid reconstruction: thyroid carcinoma invading the larynx. Case Rep Otolaryngol 2014;2014:671902.

28 Gaissert HA, Honings J, Grillo HC, et al. Segmental laryngotracheal and tracheal resection for invasive thyroid carcinoma. Ann Thorac Surg 2007;83:1952-9. 